\title{
The Tyrosine Kinase Inhibitor Tyrphostin AG 126 Reduces the Development of Colitis in the Rat
}

\author{
Salvatore Cuzzocrea, Michelle C. McDonald, Emanuela Mazzon, Helder Mota-Filipe, \\ Valeria Lepore, Antonio Ciccolo, Maria Luisa Terranova, Domenico Britti, \\ Achille P. Caputi, Christoph Thiemermann
}

Institute of Pharmacology (SC, APC), Department of Biomorphology (EM), School of Medicine, Institute of General Surgery (VL, AC, MLT), and Department of Veterinary Medicine and Pharmacology (DB), University of Messina, Italy; and The William Harvey Research Institute (MCM, HM-F, CT), St. Bartholomew's and The Royal London School of Medicine and Dentistry, London, United Kingdom

\begin{abstract}
SUMMARY: Inflammatory bowel disease is characterized by oxidative and nitrosative stress, leukocyte infiltration, up-regulation of the expression of intercellular adhesion molecule-1 (ICAM-1), and up-regulation of P-selectin in the colon. Here we investigate the effects of the tyrosine kinase inhibitor, Tyrphostin AG 126, in rats subjected to experimental colitis. Colitis was induced in rats by intracolonic instillation of dinitrobenzene sulfonic acid (DNBS). Rats experienced hemorrhagic diarrhea and weight loss. Four days after administration of DNBS, the mucosa of the colon exhibited large areas of necrosis. Neutrophil infiltration (determined by histology as well as an increase in myeloperoxidase activity in the mucosa) was associated with up-regulation of ICAM-1 and P-selectin, as well as high tissue levels of malondialdehyde. Immunohistochemistry for nitrotyrosine and poly(ADP-ribose) polymerase showed an intense staining in the inflamed colon. Staining with an anti-COX-2 antibody of sections of colon obtained from DNBS-treated rats showed a diffuse staining of the inflamed tissue. Furthermore, expression of inducible nitric oxide synthase was found mainly in macrophages located within the inflamed colon of DNBS-treated rats. Tyrphostin AG 126 (5 mg/kg daily ip) significantly reduced the degree of hemorrhagic diarrhea and weight loss caused by administration of DNBS. Tyrphostin AG 126 also caused a substantial reduction of (1) the phosphorylation of tyrosine residues of proteins (immunoblots of inflamed colon), (2) the degree of colonic injury, (3) the rise in myeloperoxidase activity (mucosa), (4) the increase in the tissue levels of malondialdehyde, (5) the increase in staining (immunohistochemistry) for nitrotyrosine and poly(ADP-ribose) polymerase, as well as (6) the up-regulation of ICAM-1 and P-selectin caused by DNBS in the colon. Thus, we provide the first evidence that the tyrosine kinase inhibitor Tyrphostin AG126 reduces the degree of colitis caused by DNBS. (Lab Invest 2000, 80:1439-1453).
\end{abstract}

$P$ Poston hosphorylation of proteins on tyrosine residues by protein tyrosine kinases plays an important role in the regulation of cell proliferation, cell differentiation, and signaling processes in cells of the immune system. The receptor tyrosine kinases participate in transmembrane signaling, whereas the intracellular tyrosine kinases take part in the signal transduction to the nucleus. Enhanced activity of tyrosine kinases has been implicated in the pathophysiology of many diseases associated with local (atherosclerosis, psoriasis) or systemic inflammation, including sepsis and septic shock (Levitzki and Gazit, 1995).

Inhibition of the activity of tyrosine kinases attenuates the expression of the genes of the proinflammatory cytokines tumor necrosis factor (TNF $\alpha)$, interleukin (IL)-1, IL-6, and interferon- $\gamma$ (Geng et al, 1993; Dinarello, 1996). Several tyrosine kinase inhibitors, including Tyrphostin AG 126, prevent the expression of several pro-inflammatory proteins, including the

Received June 2, 2000.

Address reprint requests to: Dr. Salvatore Cuzzocrea, Institute of Pharmacology, School of Medicine, University of Messina, Torre Biologica, Policlinico Universitario Via C. Valeria, Gazzi, 98100 Messina, Italy. Fax 39 090 694951; E-mail: salvator@www.unime.it inducible isoform of cyclooxygenase (COX-2) (Akarasereenont and Thiemermann, 1996; Kengatharan et al, 1996) and the inducible isoform of nitrous oxide (NO) synthase (iNOS) (Akarasereenont et al, 1995; Kengatharan et al, 1996). An increase in iNOS activity has been documented in the colon of animals with experimental colitis (Zingarelli et al, 1999a) and in patients with Crohn's disease or ulcerative colitis (Miller et al, 1995; Ikeda et al, 1997). It has been postulated that the deleterious effects of $\mathrm{NO}$ are mediated, at least in part, by peroxynitrite, a potent oxidant produced by the reaction of NO and superoxide anion (Beckman et al, 1990). Peroxynitrite is cytotoxic via a number of independent mechanisms including (1) the initiation of lipid peroxidation, (2) the inactivation of enzymes (eg, mitochondrial respiratory enzymes and membrane pumps) (Crow and Beckman, 1995), and (3) depletion of glutathione (Phelps et al, 1995). Moreover, peroxynitrite can also cause DNA damage (Inoue and Kawanishi, 1995), resulting in the activation of the nuclear enzyme poly(ADP-ribose) polymerase [PARP; also known as poly(ADP-ribose) synthetase, PARS], depletion of NAD and ATP, and ultimately cell death (Szabó et al, 1997, 1998). The activation of PARP may also play an important role in 
various experimental models of inflammation, including colitis (Cuzzocrea et al, 1997; Thiemermann et al, 1997; Zingarelli et al, 1999b).

We have hypothesized that the inhibition of the activity of protein tyrosine kinases may represent a novel approach for treatment of inflammation. Many previous strategies aimed at reducing inflammation have been limited to targeting a single mediator in one compartment of the body (Tracey et al, 1987; Fisher et al, 1993, 1996; Abraham et al, 1995). In contrast, tyrosine kinase inhibitors act directly on cells, not on mediators. Thus, inhibitors of tyrosine kinase activity should reduce the formation and/or effects of proinflammatory cytokines (eg, TNF $\alpha$ and IL-1), the expression of iNOS and COX-2, and the activation of the transcription factor NF- $\kappa \mathrm{B}$ (Guy et al, 1991; Glaser et al, 1992; Novogrodsky et al, 1994). Although all of these effects of inhibitors of tyrosine kinase should be "anti-inflammatory" in nature, there are few studies that investigate the effects of tyrosine kinase inhibitors in animal models of acute and chronic inflammation.

A family of tyrosine kinase inhibitors, the tyrphostins, which are derivatives of benzylidene malononitrile, have recently been discovered. Here we investigate the effects of Tyrphostin AG 126 on the inflammatory response (colitis) caused by intracolonic administration of dinitrobenzene sulfonic acid (DNBS). In particular, we investigate the effects of Tyrphostin AG 126 on the colon injury associated with DNBSinduced colitis. To gain a better insight into the mechanism of action of Tyrphostin AG 126, we also investigate the effects of Tyrphostin AG 126 on the expression of iNOS and COX-2 protein (by immunohistochemistry) and activity and peroxynitrite forma- tion and activation of the nuclear enzyme PARP (by immunohistochemistry).

\section{Results}

\section{Effects of Tyrphostin AG 126 on the Degree of Colitis (Histology)}

Four days after intracolonic administration of DNBS, the colon appeared flaccid and filled with liquid stool. The cecum, colon, and rectum showed evidence of mucosal congestion, erosion, and hemorrhagic ulcerations (see Fig. 1 for damage score). The histopathological features included a transmural necrosis and edema and a diffuse leukocyte cellular infiltrate in the submucosa (Fig. 2A). The inflammatory changes of the intestinal tract were associated with an increase in the weight of the colon (Fig. 3B). Treatment of rats with Tyrphostin AG 126 significantly attenuated the extent and severity of the histological signs of colonic injury (Figs. 2B and 3B). A significant increase in the weight of the spleen, an indicator of inflammation, was also noted in vehicle-treated rats that had received DNBS (Fig. 3A). No significant increase in weight of either colon or spleen was observed in DNBS-rats that had been treated with Tyrphostin AG 126 (Fig. 3). The survival of animals was monitored for 7 days. DNBSrats that had received vehicle developed severe hemorrhagic diarrhea, and $40 \%$ and $80 \%$ of these animals died within 2 and 6 days, respectively, after DNBS administration. In contrast, only $20 \%$ of the rats that had been treated with Tyrphostin AG 126 had hemorrhagic diarrhea and died (Fig. 4). The surviving rats

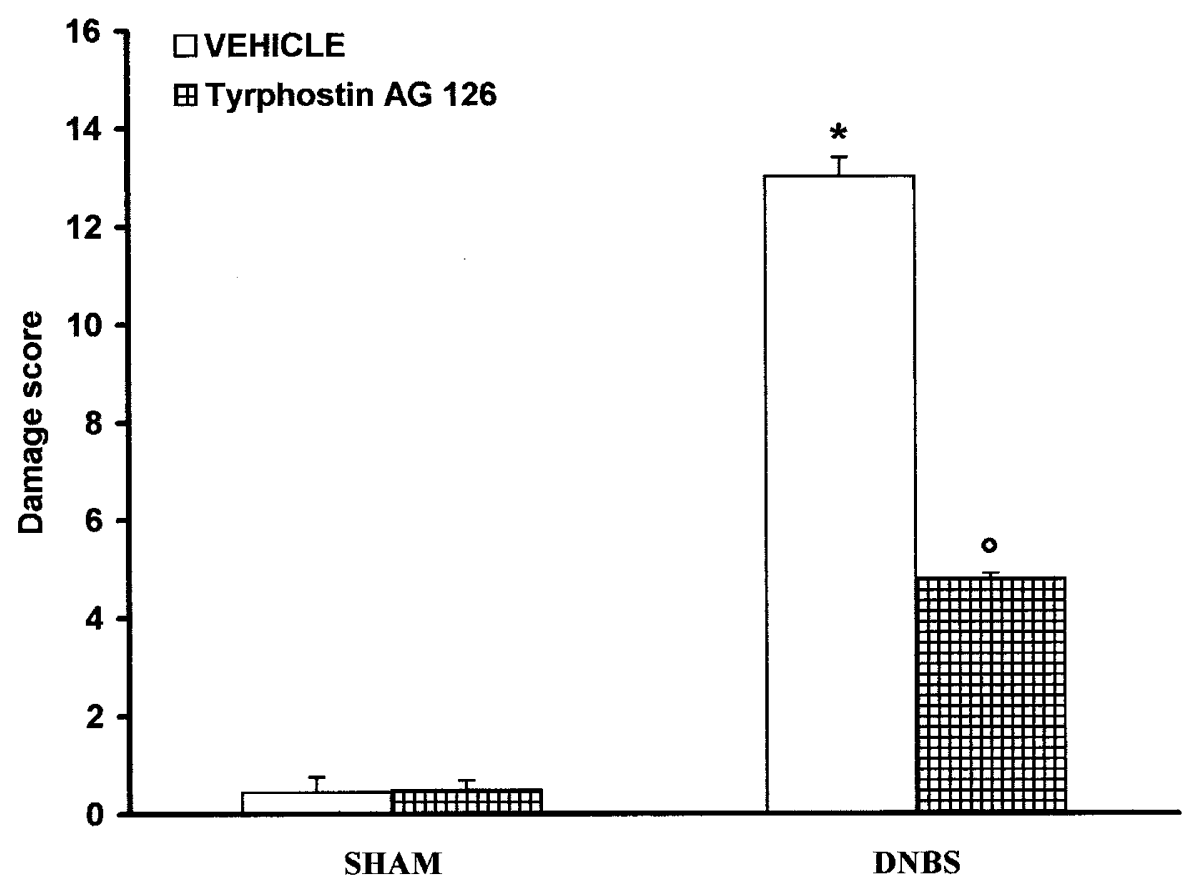

Figure 1.

Effect of Tyrphostin AG 126 treatment on the damage score. Colonic damage was scored on a scale of 0 (normal) to 10 (severe) by two independent observers. Values are means \pm SEM of 10 rats for each group. ${ }^{*} p<0.01$ versus sham; ${ }^{\circ} p<0.01$ versus DNBS. 

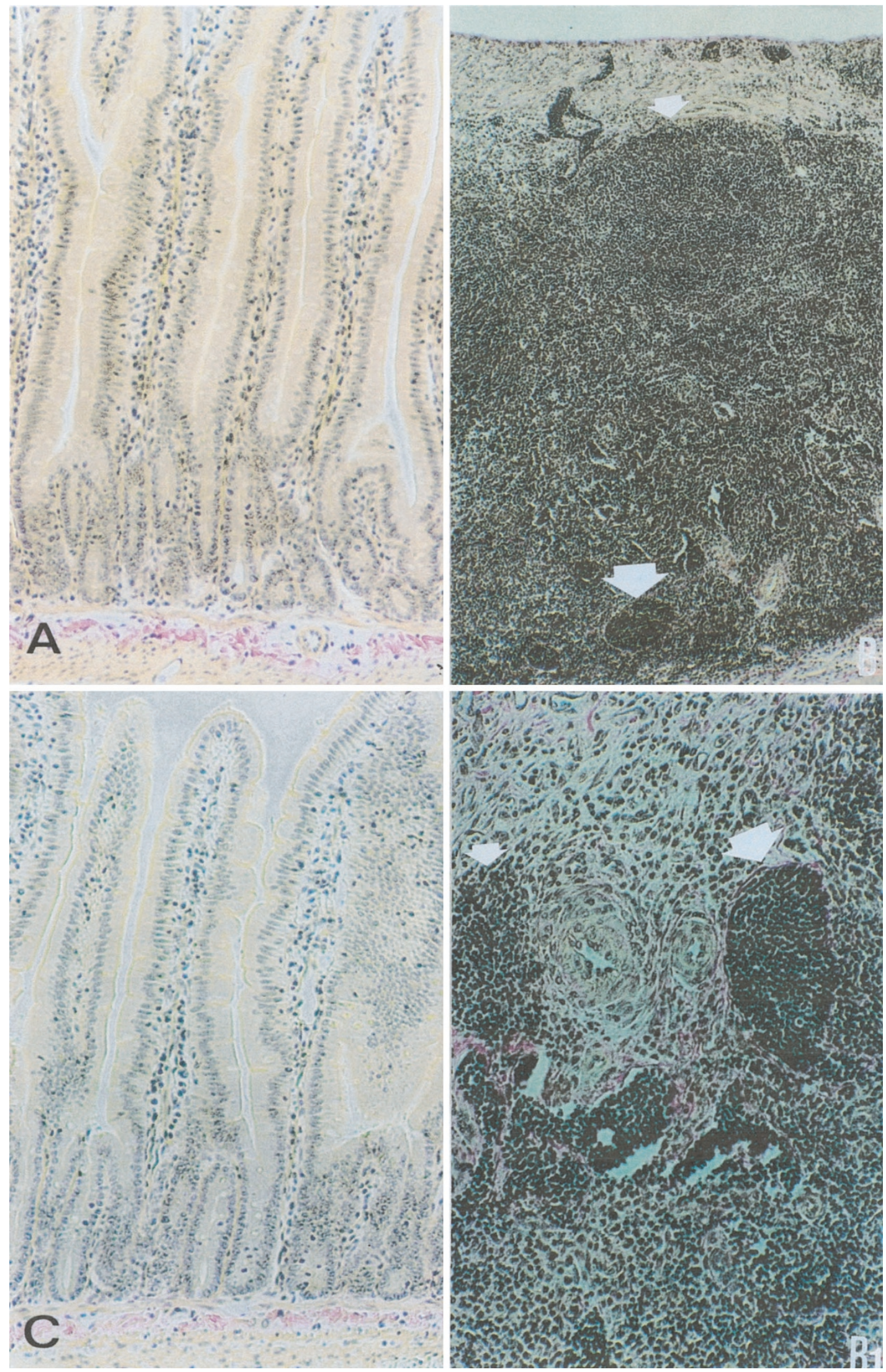

Figure 2.

Effect of Tyrphostin AG 126 on colon injury. No histological modification was present in the control animals (A). Mucosal injury was produced after DNBS administration characterized by absence of epithelium (B) and a massive mucosal and submucosal infiltration of inflammatory cells (B1). Treatment with Tyrphostin AG 126 (C) corrected the disturbances in morphology associated with DNBS administration. Original magnifications, A, B, and C, $\times 125 ; B 1, \times 250$. 

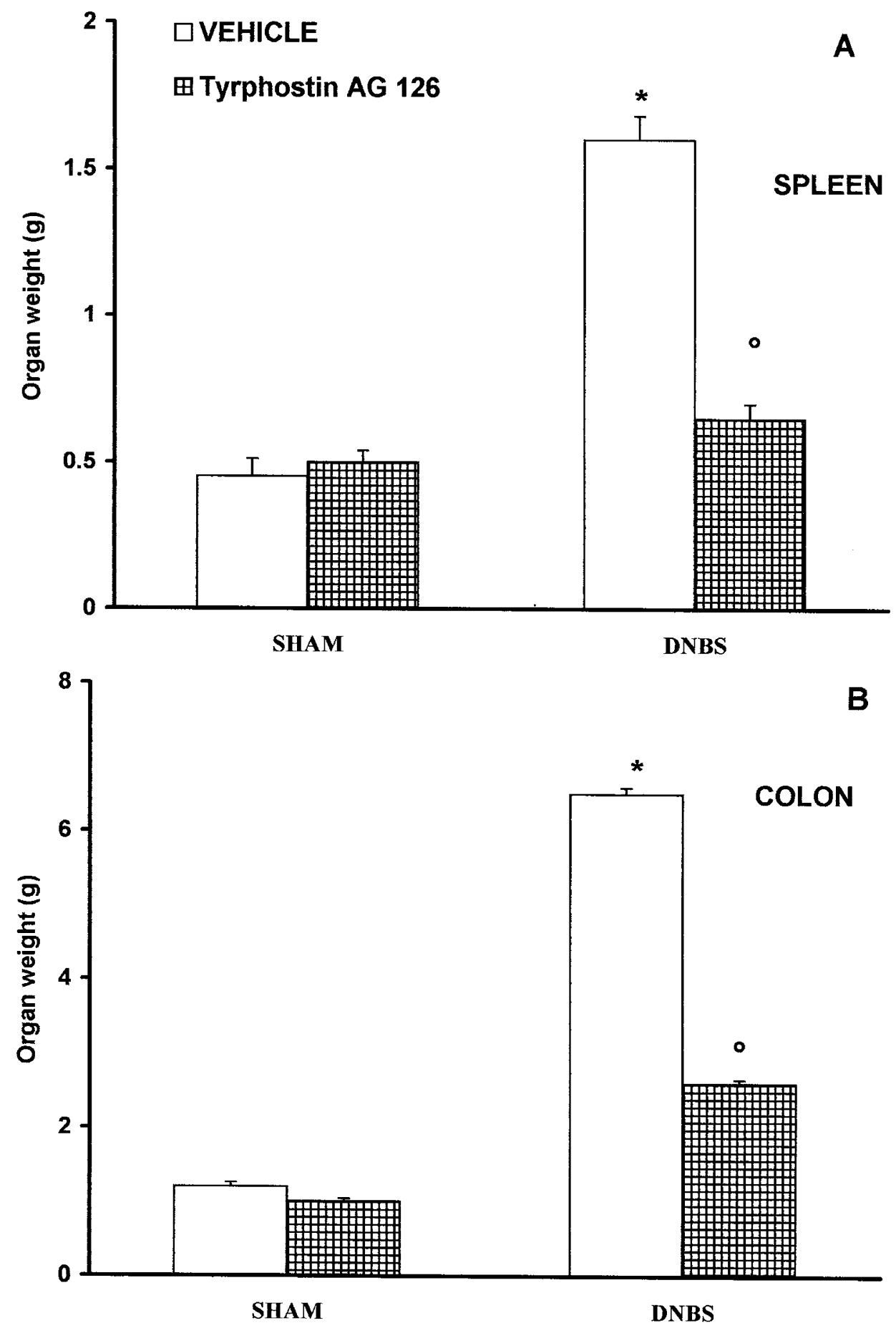

Figure 3.

Organ weight. A significant increase was consistently seen at 4 days after DNBS injection in spleen (A) and colon (B). The weight of the organs was significantly reduced in the rats that had been treated with Tyrphostin AG 126. Values are means \pm SEM of 10 rats for each group. ${ }^{\star} p<0.01$ versus sham; ${ }^{\circ} p<0.01$ versus DNBS.

appeared healthy and showed a very mild degree of diarrhea.

\section{Effects of Tyrphostin AG 126 on Changes of Body Weight}

In vehicle-treated rats, the severe colitis caused by DNBS was associated with a significant loss in body weight (Fig. 5). Treatment of DNBS-rats with Tyrphos- tin AG 126 significantly reduced the loss in body weight.

\section{Effect of Tyrphostin AG 126 on Cytokine Production}

The levels of TNF $\alpha$ and IL-1 $\beta$ were significantly elevated in the colon at 4 days after DNBS treatment. In contrast, the levels of these cytokines were significantly lower in 


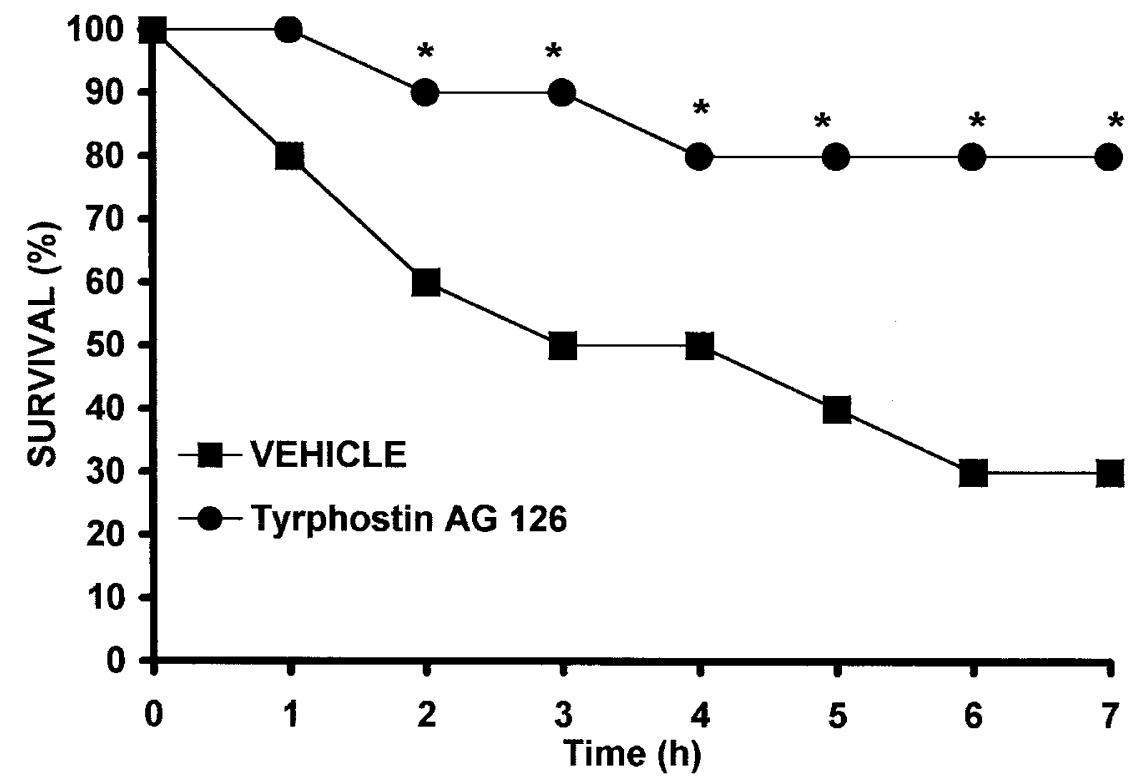

\section{Figure 4.}

Effect of Tyrphostin AG 126 treatment on DNBS-induced mortality. Survival is significantly improved in Tyrphostin AG 126-treated rats compared with the high mortality rate of the DNBS-treated rat. $n=10$ rats for each group. ${ }^{*} p<0.01$ versus DNBS.

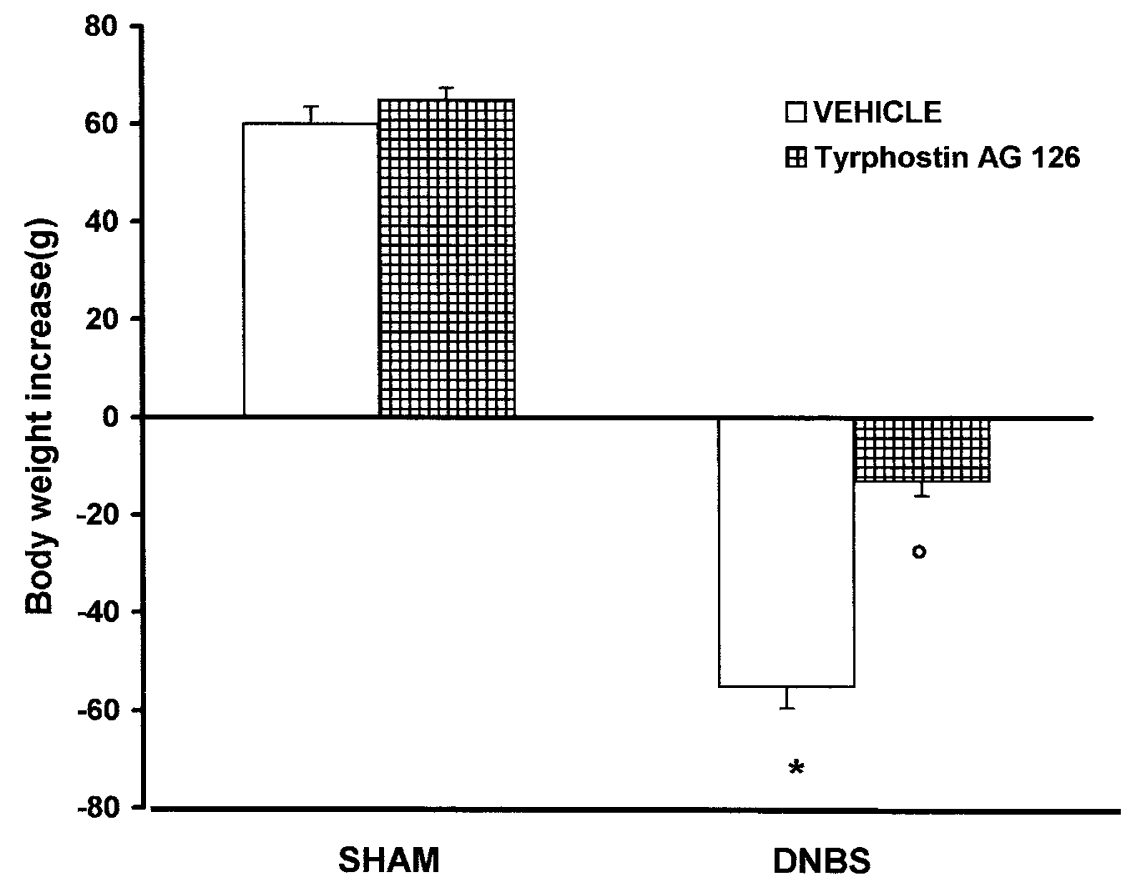

\section{Figure 5.}

Effect of Tyrphostin AG 126 treatment on body weight changes 4 days after DNBS intracolonic administration. Body weight was recorded immediately before DNBS administration and at the end of the experimental period. Tyrphostin AG 126 treatment significantly prevents the loss of body weight. Values are means \pm SEM of 10 rats for each group. ${ }^{\star} p<0.01$ versus sham; ${ }^{\circ} p<0.01$ versus DNBS

rats treated with Tyrphostin AG 126 (Fig. 6). No significant increase in the levels of cytokines was observed in the colon of sham-administered rats.

\section{Effect of Tyrphostin AG 126 on Nitric Oxide Production and COX-2 Expression}

In the colons obtained from animals subjected to DNBSinduced colitis, a significant increase of iNOS activity was detected at 4 days (Fig. 7). The iNOS activity was significantly $(p<0.01)$ lower in DNBS-treated rats treated with Tyrphostin AG 126 (Fig. 7). Four days after DNBS treatment, colon sections were taken to determine the immunohistological staining for iNOS and for COX-2. Although there was negligible staining in the intestinal sections of control animals (data not shown), immunohistochemical analysis, using a specific anti- 


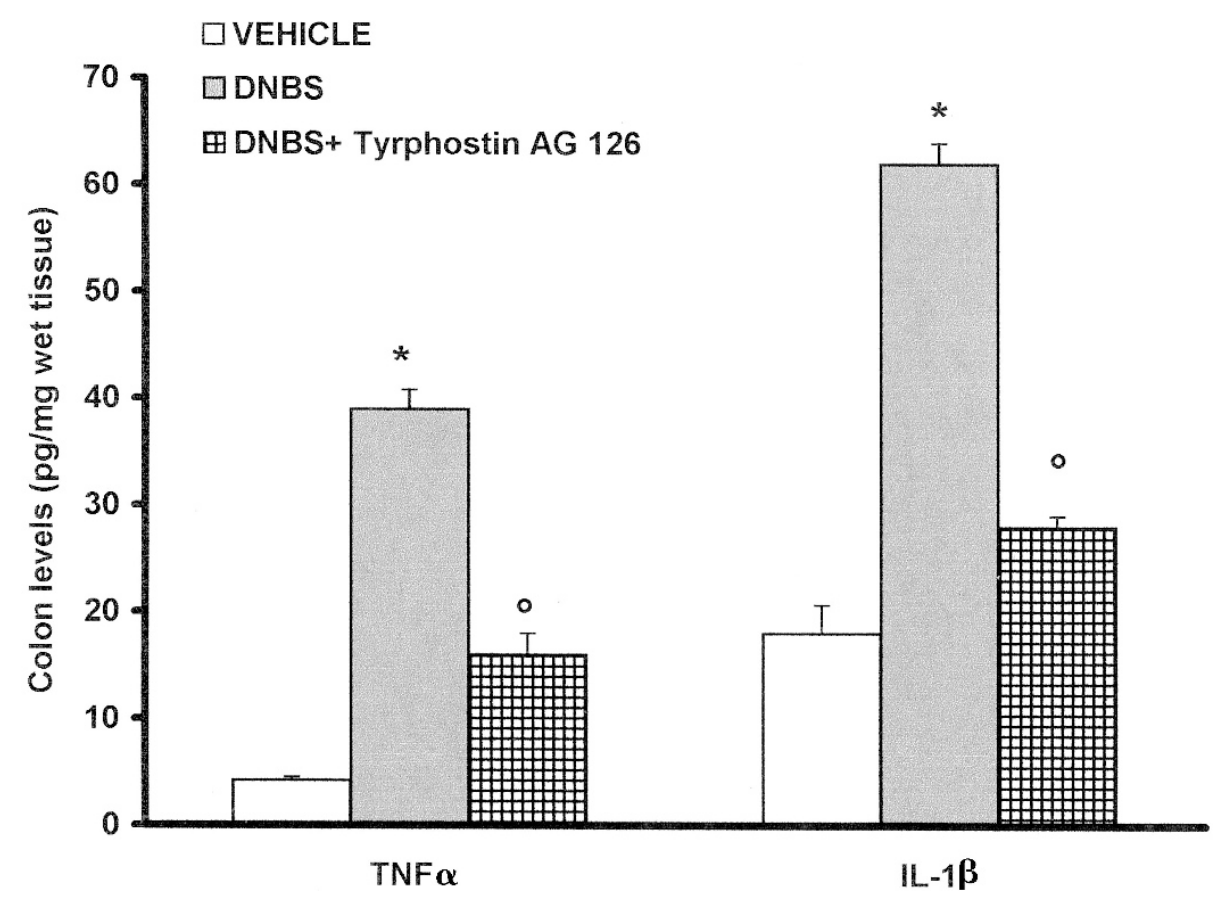

Figure 6.

Colon levels of TNF $\alpha$ and IL1 $\beta$. Cytokine levels were significantly reduced in the colon from Tyrphostin AG126-treated rats. Data are means \pm SEM OF 10 RATS FOR EACH GRouP. ${ }^{*} p<0.01$ versus sham. ${ }^{\circ} p<0.01$ versus TNBS.

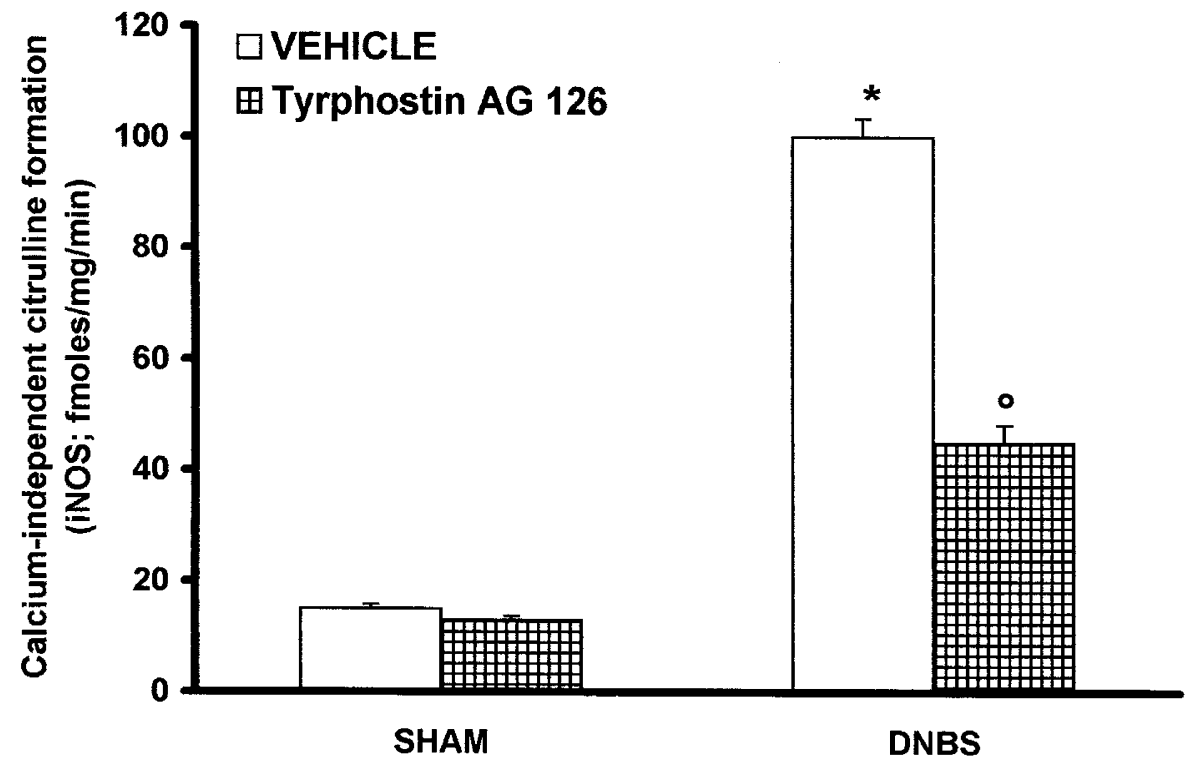

\section{Figure 7.}

Effect of Tyrphostin AG 126 treatment on iNOS activity 4 days after DNBS intracolonic administration. DNBS administration induced a significant increase in iNOS activity. Tyrphostin AG 126 treatment significantly reduced the iNOS activity. Values are means \pm SEM of 10 rats for each group. ${ }^{*} p<0.01$ versus sham; ${ }^{\circ} p<0.01$ versus DNBS.

iNOS antibody and a specific anti-COX-2 antibody, revealed a positive staining primarily localized in the infiltrated inflammatory cells and in disrupted epithelial cells (Fig. 8, A and B, respectively). As demonstrated in Figure $8 \mathrm{C}$, the positive staining for iNOS and for COX-2 protein are colocalized in inflammatory cells and in disrupted epithelial cells. Tyrphostin AG 126 reduced the degree of immunostaining for iNOS and COX-2 in the colon of DNBS-treated rats (Fig. 8, D to F).

\section{Effect of Tyrphostin AG 126 on Nitrotyrosine Formation and PARP Activity}

To determine the localization of "peroxynitrite formation" and/or other nitrogen derivatives produced dur- 

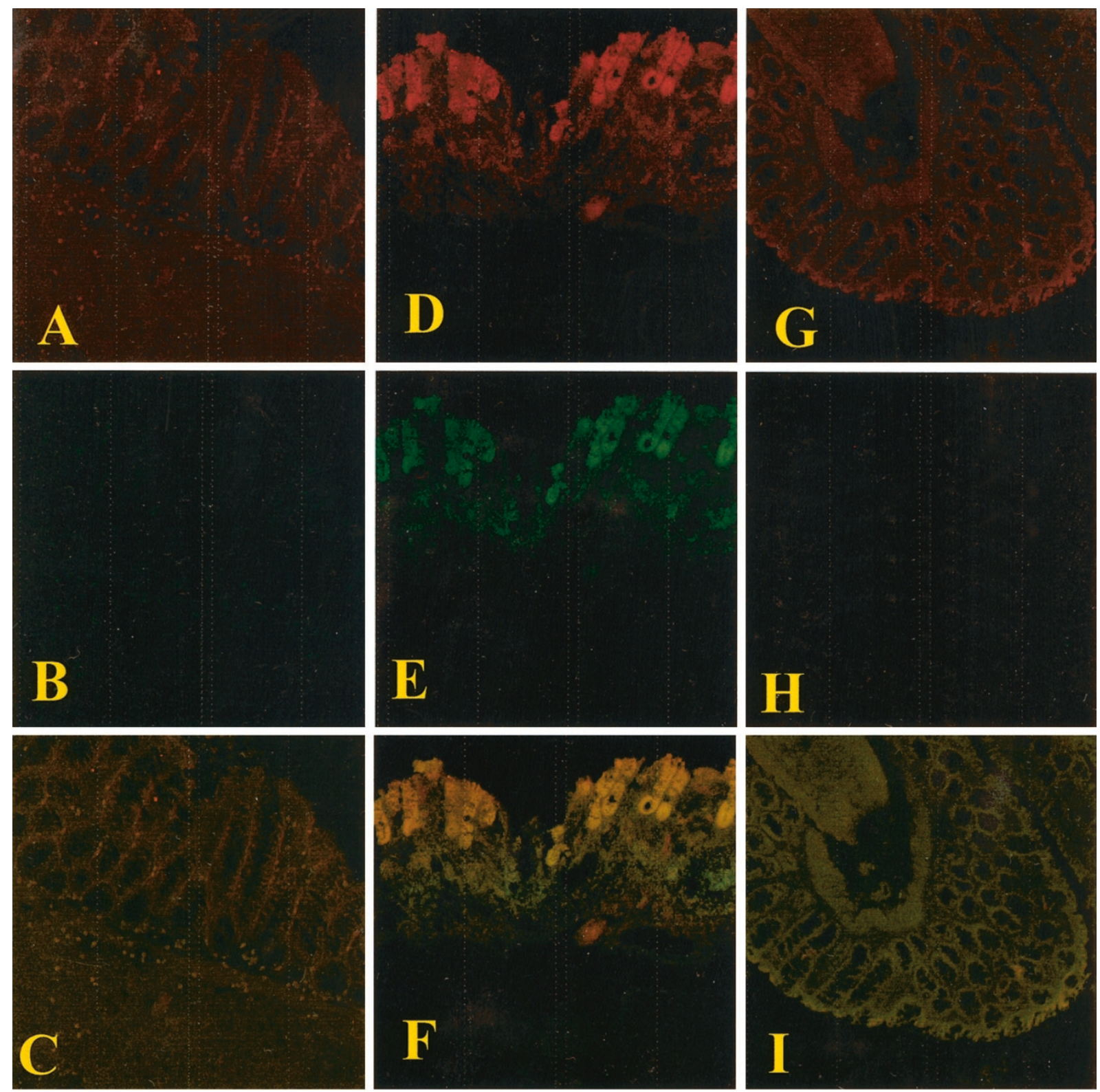

\section{Figure 8.}

Immunohistochemical localization for COX-2 and for iNOS in the colon. No positive staining for COX-2 (A) or for iNOS (B) was found in the colon section from sham-operated rats. Immunohistochemistry for COX-2 (D) and for iNOS (E) shows positive staining localized in the injured area from DNBS-treated rats. The intensity of the positive staining for $\operatorname{COX}-2(G)$ and for $\operatorname{NNS}(H)$ was significantly reduced in the ileum from Tyrphostin AG 126-treated rats. Panels C, F, and I represent the staining combination of panels $A$ and $B, D$ and $E$, and $G$ and $H$, respectively. Original magnification, $\times 32$. Figure is representative of at least 3 experiments performed on different experimental days.

ing colitis, nitrotyrosine, a specific marker of nitrosative stress, was measured by immunohistochemical analysis in the distal colon. Four days after DNBS treatment, sections of the colon were taken to determine the immunohistological staining for PARP. Sections of colon from sham-administered rats did not stain for either nitrotyrosine or PARP (Fig. 9, A and B). Colon sections obtained from vehicle-treated DNBSrats exhibited positive staining for nitrotyrosine and PARP (Fig. 9, D and E), which was colocalized in inflammatory cells and in disrupted epithelial cells. Tyrphostin AG 126 reduced the degree of immuno- staining for nitrotyrosine and PARP in the colon of DNBS-treated rats (Fig. 9, G to I).

\section{Effect of Tyrphostin AG 126 on Myeloperoxidase Activity and Lipid Peroxidation in the Colon}

The colitis caused by DNBS was also characterized by an increase in myeloperoxidase (MPO) activity, an indicator of the infiltration (accumulation) of the colon by polymorphonuclear neutrophils (PMN) (Fig. 10A). This finding is consistent with the observation made with light microscopy that the colon of vehicle-treated DBNS-rats 

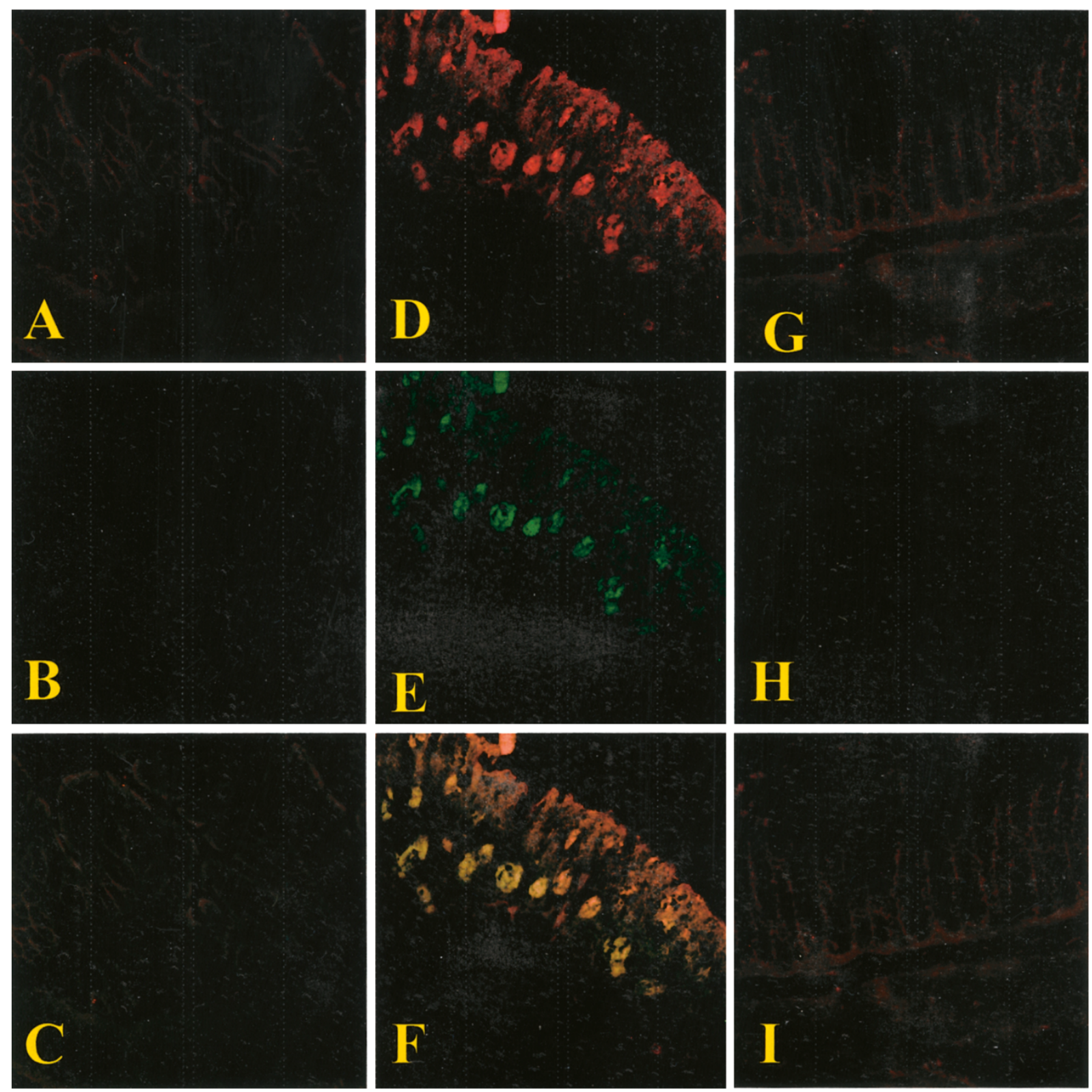

\section{Figure 9.}

Immunohistochemical localization for nitrotyrosine and for PARP in the colon. No positive staining for nitrotyrosine (A) and for PARP (B) was found in the colon section from sham-operated rats. Immunohistochemistry for nitrotyrosine (D) and for PARP (E) shows positive staining localized in the injured area from DNBS-treated rats. The intensity of the positive staining for nitrotyrosine $(G)$ and for PARP $(H)$ was significantly reduced in the ileum from Tyrphostin AG 126-treated rats. Panels $C, F$, and I represent the staining combination of panels $A$ and $B, D$ and $E$, and $G$ and $H$, respectively. Original magnification, $\times 32$. Figure is representative of at least 3 experiments performed on different experimental days.

contained a large number of PMN. Infiltration of leukocytes into the mucosa has been suggested to contribute significantly to the tissue necrosis and mucosal dysfunction associated with colitis, because activated PMN release large amounts of free radicals. The increase in MPO activity in the colon correlated positively with the increase in tissue levels of malondialdehyde, indicating an increase in lipid peroxidation (Fig. 10B). Treatment of DNBS-rats with Tyrphostin AG 126, however, significantly reduced both the degree of PMN infiltration, determined as an increase in MPO activity, and the associated lipid peroxidation, determined as an increase in tissue malondialdehyde (MDA) levels (Fig. 10).

\section{Effect of Tyrphostin AG 126 on P-Selectin and ICAM-1 Expression}

To further elucidate the effect of Tyrphostin AG 126 on neutrophil accumulation in inflamed colon, we evaluated the intestinal expression of the intercellular adhesion molecule-1 (ICAM-1) and P-selectin. Tissue sections from sham-administered rats, stained with 

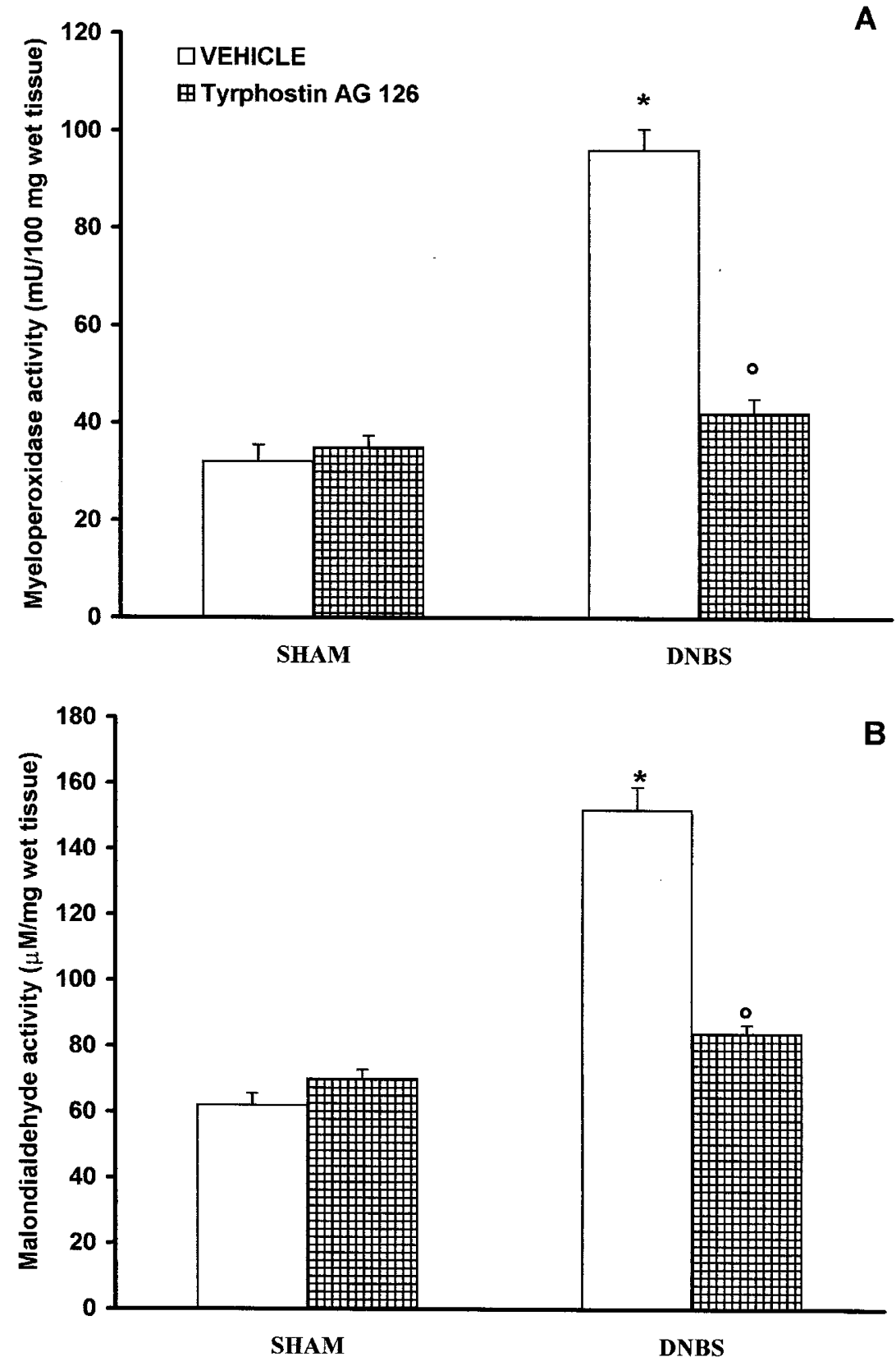

Figure 10.

Effect of Tyrphostin AG 126 on neutrophil infiltration and lipid peroxidation. myeloperoxidase (MP0) activity (A) and malondialdehyde (MDA) (B) in the colon from DNBS-treated rats. MPO activity and MDA levels were significantly increased in DNBS-treated rats compared with sham-treated rats. Tyrphostin AG 126-treated rats show a significant reduction of MPO activity and MDA levels. Values are means \pm SEM of 10 rats for each group. ${ }^{\star} p<0.01$ versus sham; ${ }^{\circ} p<0.01$ versus DNBS.

anti-ICAM-1 antibody, showed a specific staining along the vessels, demonstrating that ICAM-1 is expressed constitutively in endothelial cells (Fig. 11A). After DNBS administration, the staining intensity substantially increased in the vessels of the lamina propria and submucosa. Immunohistochemical staining for ICAM-1 was also present in epithelial cells of injured colon and in infiltrated inflammatory cells in damaged tissues from DNBS-treated rats (Fig. 11D). Tissue sections from Tyrphostin AG 126-treated rats did not reveal any up-regulation of the constitutive ICAM-1, which was normally expressed in the endothelium along the vascular wall (Fig. 11G). No positive staining with anti-P-selectin antibody was observed in tissue sections obtained from sham-administered rats (Fig. 11B). Tissue sections of colon obtained from DNBStreated rats showed positive staining for $\mathrm{P}$-selectin localized in the vascular endothelium (Fig. 11E). In tissue obtained from Tyrphostin AG 126-treated rats, no expression of $\mathrm{P}$-selectin (Fig. 11H) was found. As can be seen in Figure $11 \mathrm{E}$, positive staining for $\mathrm{P}$-selectin and for ICAM-1 are colocalized in the endothelium. 

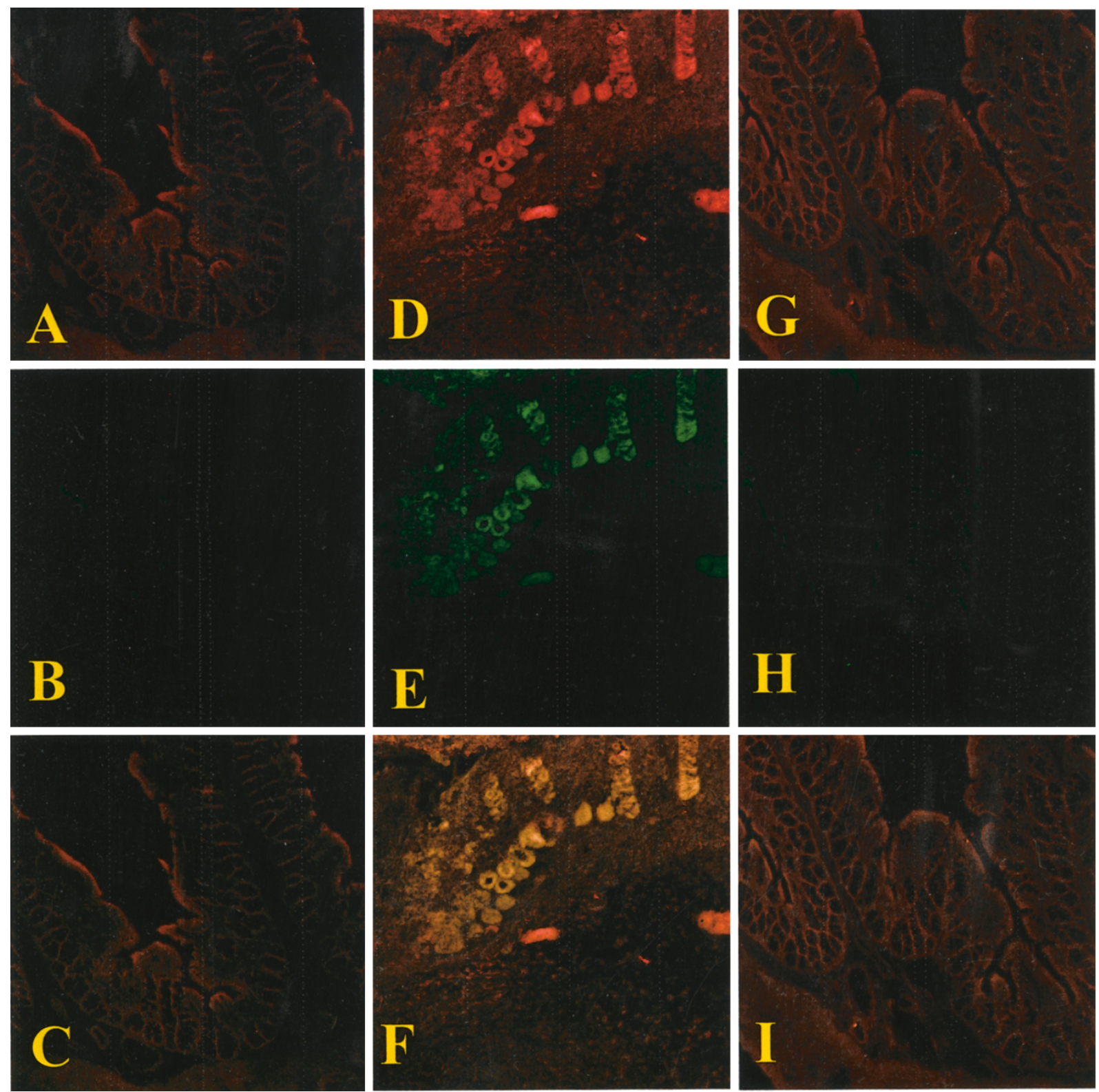

\section{Figure 11}

Immunohistochemical localization of P-selectin in the colon. Staining of colon tissue sections obtained from sham-operated rats with anti-ICAM-1 antibody showed a specific staining along vessels, demonstrating that ICAM-1 is constitutively expressed (A). lleum section from sham-operated rats revealed no positive staining for P-selectin (B). Sections from DNBS-treated rats showed intense positive staining for ICAM-1 (D) and for P-selectin (E) on endothelial cells. The degree of endothelial staining for ICAM-1 (G) and for P-selectin (H) was markedly reduced in tissue sections obtained from Tyrphostin AG 126-treated rats. Panels C, F, and I represent the staining combination of panels $A$ and $B, D$ and $E$, and $G$ and $H$, respectively. Original magnification, $\times 32$. Figure is representative of at least 3 experiments performed on different experimental days.

\section{Effect of Tyrphostin AG 126 on Tyrosine Phosphorilation in the Colon}

Using Western blotting, immunoreactivity for tyrosine phosphorylation was also detected. In colon tissues from sham-operated rats (Fig. 12, Lane A), no significant tyrosin phosphorylation was found. However, there was a marked increase in the tyrosine phosphorylation immunoreactivity in colon tissues from DNBS-treated rats (Lane B). Tyrosine phosphorylation in DNBS-treated rats was most notable in proteins of approximately $194 \mathrm{kD}$ and $116 \mathrm{kD}$ (Lane B).
Treatment with Tryphostin AG 126 significantly reduced the tyrosine phosphorylation (Lane C).

\section{Discussion}

This study provides the first evidence that pretreatment of rats with Tyrphostin AG 126 attenuates (1) the colon injury (histology), (2) the infiltration of the colon with PMN (histology and MPO activity), and (3) the degree of lipid peroxidation in the colon caused by DNBS in the rat. All of these findings support the view that the protein 


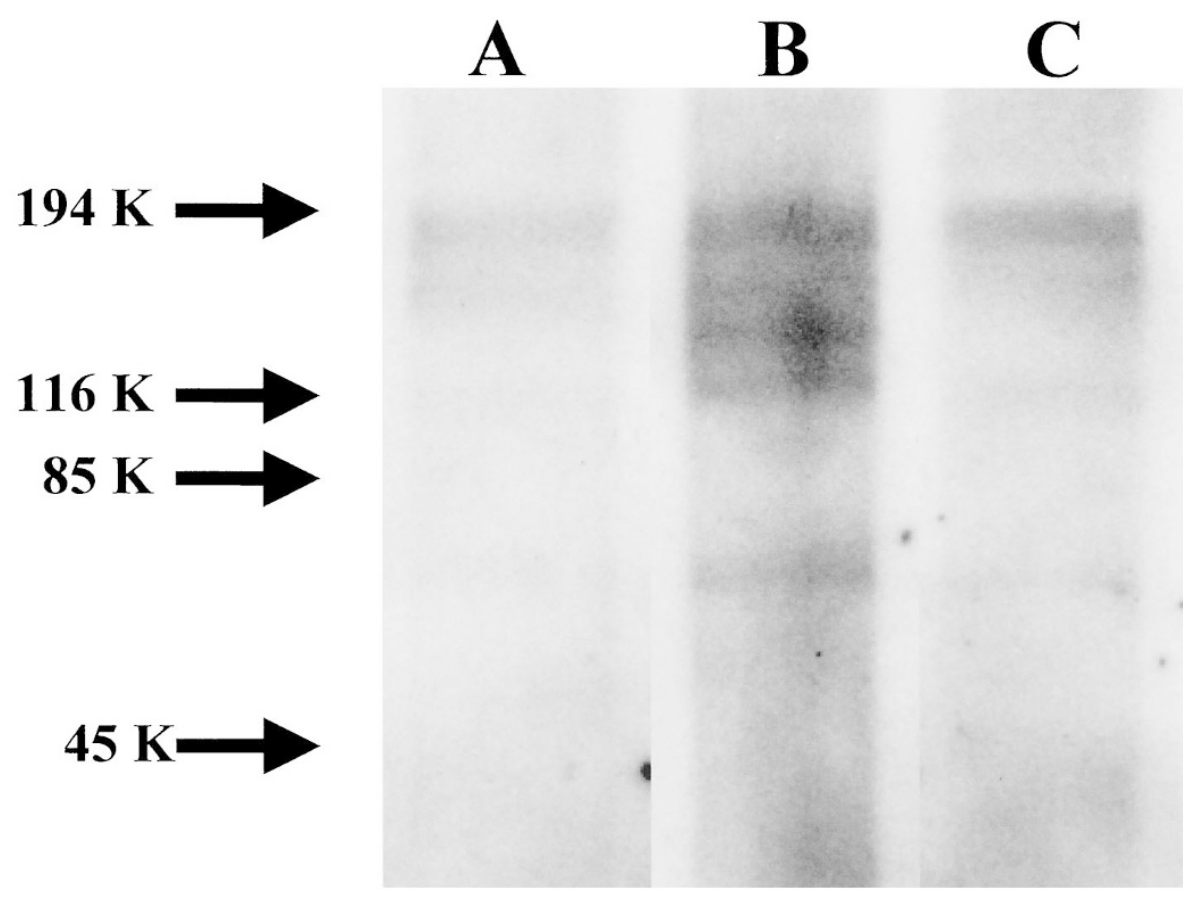

Figure 12.

Western blot for tyrosine phosphorylation. Ileum from sham-operated rats revealed no significant tyrosine phosphorylation (Lane A). DNBS-induced colitis induced a significant increase in proteins containing phosphorylated tyrosine residues (Lane B). Treatment of the animals with Tyrphostin AG 126 significantly reduced the tyrosine phosphorylation (Lane C).

tyrosine kinase inhibitor Tyrphostin AG 126 exerts potent anti-inflammatory effects in experimental colitis.

What, then, is the mechanism by which Tyrphostin AG 126 protects the colon against this inflammatory injury? We demonstrate here that Tyrphostin AG 126 (at a dose that reduces the degree of colitis caused by DNBS) abolishes the increase in tyrosine phosphorylation observed in the colon of rats with DNBSinduced colitis. This finding supports the view that the dose of Tyrphostin AG 126 used in this study is sufficient to inhibit the activity of tyrosine kinases in vivo. The assay used (eg, Western blot using an antibody against phosphorylated tyrosine residues in proteins) does not, however, indicate which specific tyrosine kinases are inhibited by Tyrphostin AG 126.

Inhibitors of the activity of protein tyrosine kinases reduce (among other effects) the biosynthesis and/or the effects of the pro-inflammatory cytokines TNF $\alpha$ and IL-1. There is good evidence that $\mathrm{TNF} \alpha$ and IL-1 help to propagate the extension of a local or systemic inflammatory process (Saklatvala, 1986; Guy et al, 1991; Wooley et al, 1993). We confirm that the models of colitis used here lead to a substantial increase in the levels of TNF $\alpha$ and IL- 1 in the colon. Interestingly, the levels of these two pro-inflammatory cytokines are significantly lower in the animals that were treated with Tyrphostin AG 126. We propose that at least some of the antiinflammatory effects of Tyrphostin AG 126 reported here are due to prevention by this tyrosine kinase inhibitor of the formation of TNF $\alpha$ and IL-1 in the colon.

Although there is good evidence that $\mathrm{TNF} \alpha$ (and $\mathrm{IL}-1)$ causes the activation and translocation of nuclear factor $-\kappa \mathrm{B}(\mathrm{NF}-\kappa \mathrm{B})$ into the nucleus, there is also evidence that (1) tyrosine phosphorylation itself plays an important role in the activation of $\mathrm{NF}-\kappa \mathrm{B}$, and (2) that tyrosine kinase inhibitors diminish the activation of NF- $\kappa$ B (Kwon et al, 1995; Mahon and O'Neill, 1995; Nishiya et al, 1995). Thus, it is possible that Tyrphostin AG 126 prevents the activation of NF- $\kappa \mathrm{B}$ either by an indirect effect (eg, prevention of the formation of TNF $\alpha$, see above) or by a direct effect. Suppression of the activation of NF- $\kappa \mathrm{B}$ by Tyrphostin AG 126 may well result in a reduced expression of enzymes (eg, iNOS, COX-2), cytokines (TNF $\alpha, \mathrm{IL}-1 \beta$, IL-6, etc.), or adhesion molecules (ICAM-1, VCAM-1, E-selectin) known to play an important role in the pathophysiology of inflammation.

In the rat, DNBS causes an overproduction of NO due to induction of iNOS, which contributes to the inflammatory process (Zingarelli et al, 1998, 1999a). We demonstrate here that Tyrphostin AG 126 attenuates the expression of iNOS in the colon from DNBStreated rats. Thus, the reduction of the expression of iNOS by Tyrphostin AG 126 may contribute to the attenuation by this agent of the formation of nitrotyrosine in the colon of DNBS-treated rats. Nitrotyrosine formation, along with its detection by immunostaining, was initially proposed as a relatively specific marker for the detection of the endogenous formation "footprint" of peroxynitrite (Beckman, 1996). There is, however, recent evidence that certain other reactions can also induce tyrosine nitration; for example, the reaction of nitrite with hypochlorous acid and the reaction of MPO with hydrogen peroxide can lead to the formation of nitrotyrosine (Eiserich et al, 1998). Increased nitrotyrosine staining is considered, therefore, 
as an indication of "increased nitrosative stress" rather than as a specific marker of the generation of peroxynitrite. Thus we propose that the reduction of the expression of iNOS protein and activity caused by Tyrphostin AG 126 contributes to the reduction by this agent of the colon injury caused by DNBS in the rat.

Reactive oxygen species (ROS) and peroxynitrite produce cellular injury and necrosis via several mechanisms, including peroxidation of membrane lipids, protein denaturation, and DNA damage. ROS produce strand breaks in DNA, which triggers energyconsuming DNA repair mechanisms and activates the nuclear enzyme PARP, resulting in the depletion of its substrate nicotinamide adenine dinucleotide (NAD) in vitro and a reduction in the rate of glycolysis. Because NAD functions as a cofactor in glycolysis and the tricarboxylic acid cycle, NAD depletion leads to a rapid fall in intracellular ATP. This process has been termed the "PARP Suicide Hypothesis." There is recent evidence that the activation of PARP may also play an important role in inflammation (Cuzzocrea et al, 1997; Szabó et al, 1997, 1998; Thiemermann et al, 1997; Zingarelli et al, 1999b). We demonstrate here that Tyrphostin AG 126 attenuates the increase in PARP activity in the colon from DNBS-treated rats. This finding suggests that prevention of the activation of PARP contributes to the beneficial effects of Tyrphostin AG 126 in DNBS-induced colitis. It should, however, be noted that there is no evidence that Tyrphostin AG 126 directly inhibits the activity of PARP in vivo.

The activation of tyrosine kinases plays a key role in the induction of COX-2, and tyrosine kinase inhibitors prevent the expression of COX-2 in vitro and in vivo (Akarasereenont and Thiemermann, 1996; Ruetten and Thiemermann, 1997). We report here that Tyrphostin AG 126 attenuates the expression of COX-2 protein in inflammatory cells located in the colon of DNBS-treated rats. There is good evidence in this and in other models of inflammation that an enhanced formation of prostanoids after the induction of COX-2 contributes to the pathophysiology of local inflammation and also that selective inhibitors of COX-2 exert potent anti-inflammatory effects (Futaki et al, 1993; Harada et al, 1996). We therefore propose that the observed anti-inflammatory effects of Tyrphostin AG 126 in experimental colitis are, at least in part, due to prevention of the expression of COX-2.

In conclusion, this study demonstrates that the degree of colitis caused by injection of DNBS is substantially reduced by treatment of rats with an inhibitor of protein tyrosine kinases (Tyrphostin AG 126). The mechanisms of the anti-inflammatory effects of Tyrphostin AG 126 are not entirely clear. In rats with DNBS-induced colitis, Tyrphostin AG 126 attenuates (1) the increase (in the colon) in proteins with phosphorylated tyrosine residues, (2) the formation of TNF $\alpha$ and IL-1 in the colon, (3) the expression of COX-2 and iNOS protein and activity, which results in a reduced formation of pro-inflammatory arachidonic acid metabolites and NO (and peroxynitrite), (4) the activation of PARP, and (5) the up-regulation of P-selectin and
ICAM-1, which in turn may contribute to the recruitment of PMN into the colon. The question of which specific tyrosine kinase, if any, is inhibited by Tyrphostin AG 126 warrants further investigation.

\section{Materials and Methods}

The biotin blocking kit, biotin-conjugated goat antirabbit IgG, and avidin-biotin peroxidase complex were obtained from Vector Laboratories (Burlingame, California). Primary anti-nitrotyrosine antibody was purchased from Upstate Biotechnology (Lake Placid, New York). Primary antibodies for P-selectin (CD62P) and ICAM-1 (CD54) were purchased from PharMingen (DBA, Milan, Italy). All other reagents and compounds used were purchased from Sigma Chemical Company (Sigma, St. Louis, Missouri).

\section{Data Analysis}

All values in the figures and text are expressed as mean \pm standard error of the mean (SEM) of $n$ observations. For the in vivo studies, $n$ represents the number of animals studied. In the experiments involving histology or immunohistochemistry, the figures shown are representative of at least three experiments performed on different experimental days. The results were analyzed by one-way ANOVA, then by Bonferroni post-hoc test for multiple comparisons. A $p$ value of less than 0.05 was considered significant.

\section{Animals}

Male Sprague-Dawley rats (300-350 g; Charles River, Milan, Italy) were housed in a controlled environment and provided with standard rodent chow and water. Animal care was in compliance with Italian regulations on the protection of animals used for experimental and other scientific purposes (D.M. 116192) as well as with EEC regulations (O.J. of E.C. L 358/1 12/18/1986).

\section{Experimental Groups}

Tyrphostin AG 126 was given daily as an ip bolus injection (5 mg/kg; DNBS + AG 126 group). In a vehicle-treated group of rats, vehicle (saline) was injected instead of Tyrphostin AG 126 (DNBS group). In separate groups of rats, treatment was performed in every aspect identical to the DNBS group, except that saline was given instead of DNBS (Sham group). In an additional group of animals, sham treatment was combined with the administration of Tyrphostin AG 126 (dose as above; Sham + AG 126 group).

\section{Induction of Experimental Colitis}

Colitis was induced using a technique of acid-induced inflammation of the colon as described previously (Fries et al, 1999). Fasted rats were lightly anesthetized with isoflurane, a 3.5 F catheter was inserted into the colon via the anus up to the splenic flexure $(8 \mathrm{~cm}$ from the anus). 2,4,6-dinitrobenzene sulfonic acid (DNBS; 25 mg/rat) was dissolved in 50\% ethanol (total 
volume, $0.8 \mathrm{ml}$ ). Thereafter, the animals were kept for 15 minutes in a Trendelenburg position to avoid reflux. Seven animals (sham-colitis) received an enema with vehicle alone ( $50 \%$ ethanol, $0.8 \mathrm{ml})$. After induction of colitis or sham-colitis, the animals were observed for 3 days. On Day 4, the animals were weighed and anesthetized with chloralium hydrate $(400 \mathrm{mg} / \mathrm{kg}$, ip), and the abdomen was opened by a midline incision. The colon was removed, freed from surrounding tissues, opened along the antimesenteric border, rinsed, weighed, and processed for histology and immunohistochemistry. In an additional experiment, colitis and sham-colitis were induced in 28 rats (7 animals/ group). Animals were monitored for evaluation of mortality for 7 days.

\section{Light Microscopy}

After fixation for 1 week at room temperature in Dietrich solution $(14.25 \%$ ethanol, $1.85 \%$ formaldehyde, $1 \%$ acetic acid), samples were dehydrated in graded ethanol and embedded in Paraplast (Sherwood Medical, Mahwah, New Jersey). Thereafter, 7- $\mu \mathrm{m}$ sections were deparaffinized with xylene, stained with hematoxylin-eosin and trichromic van Gieson's coloration, and observed in a Dialux 22 Leitz (Leica, Wetzlar, Germany) microscope.

\section{Localization of Nitrotyrosine, PARS, P-Selectin, ICAM-1, iNOS, and COX-2 by Immunofluorescence}

Indirect immunofluorescence staining was performed on 7 - $\mu \mathrm{m}$-thick sections of unfixed colon of the rat. Sections were cut with a Slee and London cryostat at $-30^{\circ} \mathrm{C}$, transferred onto clean glass slides and dried overnight at room temperature $(\mathrm{RT})$. Sections were permeabilized with acetone at $-20^{\circ} \mathrm{C}$ for 10 minutes and rehydrated in phosphate buffered saline (PBS; $150 \mathrm{~mm} \mathrm{NaCl,} 20 \mathrm{~mm}$ sodium phosphate, $\mathrm{pH} 7.2$ ) at RT for 45 minutes. Sections were co-incubated overnight with (1) antinitrotyrosine rabbit polyclonal antibody (1:500 in PBS, $\mathrm{v} / \mathrm{v}$ ) or with anti-poly(ADP-ribose) goat polyclonal antibody (1:500 in PBS, v/v), or (2) with primary anti-iNOS antibody (1:500 in PBS, v/v) or with anti-COX-2 antibody (1:500 in PBS, v/v), or (3) with rabbit anti-human polyclonal antibody directed at P-selectin (CD62P), which reacts with rat and with mouse anti-rat antibody directed at ICAM-1 (CD54) (1:500 in PBS, v/v) (DBA, Milan, Italy). Sections were washed with PBS, and co-incubated with secondary antibody (TRITC-conjugated anti-goat and with FITC-conjugated anti-rabbit (Jackson Immunoresearch, West Grove, Pennsylvania) antibody (1:80 in PBS, v/v) for 2 hours at RT. Sections were washed as before, mounted with 90\% glycerol in PBS, and observed with a Nikon RCM8000 confocal microscope equipped with a $40 \times$ oil objective.

\section{Detection of Tyrosin Phosphorylation by Western Blotting}

Colon was homogenized in radioimmunoprecipitation assay (RIPA) buffer on ice using a tissue homogenizer. The material was incubated on ice for 30 minutes, then centrifuged at $14,000 \mathrm{~g}$ for 20 minutes at $4^{\circ} \mathrm{C}$. Then, 50 $\mu \mathrm{g}$ of each sample was diluted in $2 \times$ volume SDStreated buffer and heated to $95^{\circ} \mathrm{C}$ for 5 minutes. Samples were then loaded into $8 \%$ to $16 \%$ Tris-glycine. Gels were run at 125 volts for 2 hours, then transferred to 0.45 $\mu \mathrm{m}$ nitrocellulose at 25 volts for 60 minutes using Towbin buffer system. Membrane was blocked in 1\% BSA: 1\% non-fat-milk in PBS-T for 1 hour, then probed with an antibody against tyrosine-phosphorylated proteins (antityrosine phosphorylation, DBA, Milan, Italy; $1 \mu \mathrm{g} / \mathrm{ml}$ in PBS-T [0.05\%] for 2 hours at RT). The blot was washed three times with PBS-T, once with $\mathrm{H}_{2} \mathrm{O}$, and incubated for 1.5 hours with secondary antibody (1:3000). Finally, $1.5 \mathrm{ml}$ of mixed ECL chemiluminescence was added for 1 minute. The blot was then exposed to $x$-ray film for 60 seconds.

\section{Myeloperoxidase Activity}

MPO activity, an indicator of PMN accumulation, was determined as previously described (Mullane et al, 1985). Four days after intracolonic injection of DNBS, the colon was removed and weighed. The colon was homogenized in a solution containing $0.5 \%$ hexadecyl-trimethyl-ammonium bromide dissolved in 10 $\mathrm{mm}$ potassium phosphate buffer $(\mathrm{pH} 7)$ and centrifuged for 30 minutes at 20,000 g at $4^{\circ} \mathrm{C}$. An aliquot of the supernatant was then allowed to react with a solution of tetra-methyl-benzidine $(1.6 \mathrm{~mm})$ and $0.1 \mathrm{~mm}$ $\mathrm{H}_{2} \mathrm{O}_{2}$. The rate of change in absorbance was measured spectrophotometrically at $650 \mathrm{~nm}$. MPO activity was defined as the quantity of enzyme degrading 1 $\mu \mathrm{mol}$ of peroxide per minute at $37^{\circ} \mathrm{C}$, and was expressed in milliunits per gram weight of wet tissue.

\section{Malondialdehyde Measurement}

The levels of MDA in the colon were determined as an indicator of lipid peroxidation (Ohkawa et al, 1979). Four days after intracolonic injection, colon was removed, weighed, and homogenized in $1.15 \% \mathrm{KCl}$ solution. An aliquot $(100 \mu \mathrm{l})$ of the homogenate was added to a reaction mixture containing $200 \mu \mathrm{l}$ of $8.1 \%$ SDS, $1500 \mu$ l of $20 \%$ acetic acid (pH 3.5), $1500 \mu$ l of $0.8 \%$ thiobarbituric acid, and $700 \mu$ distilled water. Samples were then boiled for 1 hour at $95^{\circ} \mathrm{C}$ and centrifuged at $3,000 \mathrm{~g}$ for 10 minutes. The absorbance of the supernatant was measured by spectrophotometry at $650 \mathrm{~nm}$.

\section{Measurement of Cytokines}

The levels of TNF $\alpha$ and IL-1 $\beta$ were evaluated in the colon 4 days after intracolonic injection of DNBS. The assay was performed with a colorimetric, commercial kit (Calbiochem-Novabiochem Corporation, Milan, Italy).

\section{Determination of Nitric Oxide Synthase Activity}

The calcium-independent conversion of L-arginine to L-citrulline in the homogenates of colon (obtained 3 days after DNBS treatment in the presence or the absence of Tyrphostin AG 126) served as an indicator of iNOS 
activity (Zingarelli et al, 1999a). Colon was homogenized into a buffer composed of $50 \mathrm{~mm}$ Tris. $\mathrm{HCl}, 0.1 \mathrm{~mm}$ EDTA, and $1 \mathrm{~mm}$ phenylmethylsulphonyl fluoride $(\mathrm{pH}$ 7.4) on ice using a tissue homogenizer. Conversion of $\left[{ }^{3} \mathrm{H}\right]-\mathrm{L}-$ arginine to $\left[{ }^{3} \mathrm{H}\right]$-L-citrulline was measured in the homogenates as previously described (Zingarelli et al, 1999a). Briefly, homogenates $(30 \mu l)$ were incubated in the presence of $\left[{ }^{3} \mathrm{H}\right]$-L-arginine (10 $\mu \mathrm{M}, 5 \mathrm{kBq}$ per tube), NADPH (1 mM), calmodulin (30 nM), tetrahydrobiopterin (5 $\mu \mathrm{M})$, and EGTA (2 mM) for 20 minutes at $22^{\circ} \mathrm{C}$. Reactions were stopped by dilution with $0.5 \mathrm{ml}$ of ice cold HEPES buffer (pH 5.5) containing EGTA (2 mM) and EDTA (2 mM). Reaction mixtures were applied to Dowex $50 \mathrm{~W}\left(\mathrm{Na}+\right.$ form) columns and the eluted $\left[{ }^{3} \mathrm{H}\right]$-L-citrulline activity was measured by a Beckman scintillation counter.

\section{Acknowledgements}

This study was supported by a grant from MUST (40\%). The authors would like to thank Fabio Giuffré and Carmelo La Spada for their excellent technical assistance during this study, Caterina Cutrona for secretarial assistance, and Valentina Malvagni for editorial assistance with the manuscript. CT is a senior fellow of the British Heart Foundation (FS 96/018).

\section{References}

Abraham E, Wunderink R, Silverman H, Perl TM, Nasraway S, Levy H, Bone R, Wenzel R, Balk R, Allred R, Pennington LE, and Wherry LC (1995). Efficacy and safety of monoclonal antibody to human tumor necrosis factor alpha in patients with sepsis syndrome. JAMA 273:934-941.

Akarasereenont P, Mitchell JA, Bakhle YS, Thiemermann C, and Vane JR (1995). Comparison of the induction of cyclooxygenase and nitric oxide synthase by endotoxin in endothelial cells and macrophages. Eur J Pharmacol 273:121-128.

Akarasereenont $P$ and Thiemermann $C$ (1996). The induction of cyclooxygenase-2 in human pulmonary epithelial cells culture (A549) activated by IL-1beta is inhibited by tyrosine kinase inhibitors. Biochem Biophys Res Commun 220:181-185.

Beckman JS (1996). Oxidative damage and tyrosine nitration from peroxynitrite. Chem Res Toxicol 9:836-844.

Beckman JS, Beckman TW, Chen J, Marshall PA, and Freeman BA (1990). Apparent hydroxyl radical production by peroxynitrite: Implication for endothelial injury from nitric oxide and superoxide. Proc Natl Acad Sci USA 87:1620-1624.

Crow JP and Beckman JS (1995). The role of peroxynitrite in nitric oxide-mediated toxicity. Curr Top Microbiol Immunol 196:57-73.

Cuzzocrea S, Zingarelli B, Costantino G, Szabó A, Salzman AL, Caputi AP, and Szabó C (1997). Beneficial effects of 3-aminobenzamide, an inhibitor of poly (ADP-ribose) synthetase in a rat model of splanchnic artery occlusion and reperfusion. Br J Pharmacol 121:1065-1074.

Dinarello CA (1996). Cytokines as mediators in the pathogenesis of septic shock. Curr Top Microbiol Immunol 216:133-165.

Eiserich JP, Hristova M, Cross CE, Jones AD, Freeman BA, Halliwell B, and van der Vliet A (1998). Formation of nitric oxide-derived inflammatory oxidants by myeloperoxidase in neutrophils. Nature 391:393-397.
Fisher CJ Jr, Opal SM, Dhainaut JF, Stephans S, Zimmerman JL, Nightingale P, Harris SJ, Schein RM, Panacek EA, Vincent JL, Garrard C (1993). Influence of an anti-tumor necrosis factor monoclonal antibody on cytokine levels in patients with sepsis. Crit Care Med 21:318-327.

Fisher CJ Jr, Agosti JM, Opal SM, Lowry SF, Balk RA, Sadoff JC, Abraham E, Schein RM, and Benjamin E (1996). Treatment of septic shock with the tumor necrosis factor receptor: Fc fusion protein. N Engl J Med 334:1697-1702.

Fries W, Mazzon E, Squarzoni S, Martin A, Martines D, Micali A, Sturniolo GC, Citi S, and Longo G (1999). Experimental colitis increases small intestine permeability in the rat. Lab Invest 79:49-57.

Futaki N, Arai I, Hamasaka Y, Takahashi S, Higuchi S, and Otomo S (1993). Selective inhibition of NS-398 on prostanoid production in inflamed tissue in rat carrageenan-air-pouch inflammation. J Pharm Pharmacol 45:753-755.

Geng Y, Zhang B, and Lotz M (1993). Protein tyrosine kinase activation is required for lipopolysaccharide induction of cytokines in human blood monocytes. J Immunol 151:6692-6700.

Glaser, KB, Sung A, Bauer J, and Weichman BM (1992). Regulation of eicosanoid biosynthesis in the macrophage. J Biol Chem 265:8658-8664.

Guy GR, Chua SP, Wong NS, Ng SB, and Tan YH (1991). Interleukin 1 and tumor necrosis factor activate common multiple protein kinases in human fibroblasts. J Biol Chem 266:14343-14352.

Harada $Y$, Hatanaka K, Kawamura M, Saito M, Ogino M, Majima M, Ohno T, Ogino K, Yamamoto K, Taketani Y, Yamamoto S, and Katori M (1996). Role of prostaglandin $\mathrm{H}$ synthase-2 in prostaglandin E2 formation in rat carrageenininduced pleurisy. Prastaglandins 51:19-33.

Ikeda I, Kasajima T, Ishiyama S, Shimojo T, Takeo Y, Nishikawa T, Kameoka S, Hiroe M, and Mitsunaga A (1997). Distribution of inducible nitric oxide synthase in ulcerative colitis. Am J Gastroenterol 92:1339-1341.

Inoue S and Kawanishi S (1995). Oxidative DNA damage induced by simultaneous generation of nitric oxide and superoxide. FEBS Lett 371:86-88.

Kengatharan M, De Kimpe SJ, and Thiemermann C (1996). Analysis of the signal transduction in the induction of nitric oxide synthase by lipoteichoic acid in macrophages. $\mathrm{Br} \mathrm{J}$ Pharmacol 117:1163-1170.

Kwon G, Corbett JA, Rodi CP, Sullivan P, and McDaniel ML (1995). Interleukin-1 beta-induced nitric oxide synthase expression by rat pancreatic beta-cells: Evidence for the involvement nuclear factor kappa B in the signaling mechanism. Endocrinology 136:4790-4795.

Levitzki A and Gazit A (1995). Tyrosine kinase inhibition: An approach to drug development. Science 267:1782-1788.

Mahon TM and O'Neill LA (1995). Studies into the effect of the tyrosine kinase inhibitor herbimycin A on NF-kappa B activation in T lymphocytes: Evidence for covalent modification of the p50 subunit. J Biol Chem 270:28557-28564.

Miller MJ, Thompson JH, Zhang XJ, Sadowska-Krowicka H, Kakkis JL, Munshi UK, Sandoval M, Rossi JL, ElobyChildress S, Beckman JS, Ye YZ, Rodi CP, Manning PT, Currie MG, and Clerk DA (1995). Role of inducible nitric oxide synthase expression and peroxynitrite formation in guinea pig ileitis. Gastroenterology 109:1475-1483. 
Mullane KM, Kraemer R, and Smith B (1985). Myeloperoxidase activity as a quantitative assessment of neutrophil infiltration into ischemic myocardium. J Pharmacol Methods 14:157-167.

Nishiya T, Uehara T, and Nomura $Y$ (1995). Herbimycin A suppresses NF-kappa B activation and tyrosine phosphorylation of JAK2 and the subsequent induction of nitric oxide synthase in C6 glioma cells. FEBS Lett 371:333-336.

Novogrodsky A, Vanichkin A, Patya M, Gazit A, Osherov N, and Levitzki A (1994). Prevention of lipopolysaccharideinduced lethal toxicity by tyrosine kinase inhibitors. Science 264:1319-1322.

Ohkawa H, Ohishi N, and Yagi K (1979). Assay for lipid peroxides in animal tissues by thiobarbituric acid reaction. Anal Biochem 95:351-358.

Phelps DT, Ferro TJ, Higgins PJ, Shankar R, Parker DM, and Johnson M (1995). TNF-alpha induces peroxynitritemediated depletion of lung endothelial glutathione via protein kinase C. Am J Physiol 269:L551-559.

Ruetten $\mathrm{H}$ and Thiemermann C (1997). Effects of tyrphostins and genistein on the circulatory failure and organ dysfunction caused by endotoxin in the rat: A possible role for protein tyrosine kinase. Br J Pharmacol 122:59-70.

Saklatvala J (1986). Tumour necrosis factor a stimulates resorption and inhibits synthesis of proteoglycan in cartilage. Nature 322:547-549.

Szabó C, Lim LH, Cuzzocrea S, Getting SJ, Zingarelli B, Flower RJ, Salzman AL, and Perretti M (1997). Inhibition of poly (ADP-ribose) synthetase attenuates neutrophil recruitment and exerts antiinflammatory effects. J Exp Med 186: 1041-1049.
Szabó C, Viràg L, Cuzzocrea S, Scott GS, Hake P, O'Connor M, Zingarelli B, Salzman AL, and Kun E (1998). Protection against peroxynitrite-induced fibroblast injury and arthritis development by inhibition of poly (ADP-ribose) synthetase. Proc Natl Acad Sci USA 95:3867-3872.

Thiemermann C, Bowes J, Myint FP, and Vane JR (1997). Inhibition of the activity of poly(ADP ribose) synthase reduces ischemia-reperfusion injury in the heart and skeletal muscle. Proc Natl Acad Sci USA 94:679-683.

Tracey KJ, Fong Y, Hesse DG, Manogue KR, Lee AT, Kuo GC, Lowry SI, and Cerami A (1987). Anti-cachectin/TNF monoclonal antibodies prevent septic shock during lethal bacteraemia. Nature 330:662-664.

Wooley PH, Whalen JD, Chapman DL, Berger AE, Richard KA, Aspar DG, and Staite ND (1993). The effect of an interleukin-I receptor antagonist protein on type II collageninduced arthritis and antigen-induced arthritis in mice. Arthritis Rheum 36:1305-1314.

Zingarelli B, Cuzzocrea S, Szabó C, and Salzman AL (1998). Mercaptoethylguanidine, a combined inhibitor of nitric oxide synthase and peroxynitrite scavenger, reduces trinitrobenzene sulfonic acid-induced colonic damage in rats. J Pharmacol Exp Ther 287:1048-55.

Zingarelli B, Szabó C, and Salzman AL. (1999a). Blockade of Poly(ADP-ribose) synthetase inhibits neutrophil recruitment, oxidant generation, and mucosal injury in murine colitis. Gastroenterology 116:335-45.

Zingarelli B, Szabó C, and Salzman AL. (1999b). Reduced oxidative and nitrosative damage in murine experimental colitis in the absence of inducible nitric oxide synthase. Gut 45:199-209. 